\title{
Intercultural Teaching and Learning Strategies for Global Citizens: A Chinese EFL Perspective
}

\begin{abstract}
This article reviews teaching intercultural competence in the classroom with a group of homogeneous Chinese university students. This is explored through teaching EFL (English as a Foreign Language) writing in a way that changes Chinese students' thinking. It involves a change of cultural perspectives by placing the concept of 'the individual'at the heart of their learning and writing in English. This cultural change through alternative thinking strategies demands that Chinese students critically examine their collective traditions and beliefs that have otherwise influenced their assumptions in learning and in writing in English. This article is derived from teaching strategies that facilitate change through a biographical teaching method, which ensures a personal paradigm shift in the student towards becoming a global citizen.
\end{abstract}

\section{Introduction}

Internationalization in higher education (HE) has become a competitive global market with the need to foster intercultural understanding through both policy and practice (Bodycott and Walker 2000; Gu 2009; Dolby 2010). Many universities seek ways to promote their international competitiveness by preparing their students to be part of a future global workforce with new types of competence combined to disciplinary content knowledge. This includes critical and creative thinking, written communication, and flexibility to build up intercultural knowledge and capacity that can be applied and transferred across different languages, disciplines, cultures, professions and life circumstances (Stephens, 2009). Teaching and learning to support intercultural capability takes place in both domestic and international contexts and has gained importance in response to the challenge of globalization (Crabtree and Sapp, 2004; Tani, 2008; Lutz, 2010).

Current scholarship on intercultural learning driven by the internationalization agenda of HE concentrates on multicultural and international contexts. Quite often, intercultural learning in these contexts suggests as a prerequisite major intervention in the form of physical movement between countries and cultures, where students leave their home countries and study abroad in a different culture as an "international student". The research literature focuses on students' socio-cultural experiences of studying in foreign higher education institutions, and mainly explored their difficulties, adaptation and maturity in the host culture and country, in particular, in "Western" settings (e.g. Bodycott and Walker 2000; Fu and Townsend1998; Ippolito 2007; Gu 2009; Huang, and Brown 2009). 
The internationalization of $\mathrm{HE}$ in non-Western contexts, including pedagogical curriculum and delivery issues still remains relatively unexplored. In the context of government policy and action plans to internationalize HE in China, intercultural teaching and learning has begun to receive increased attention. In this vein, this article provides an insight into teaching practices that aim to actualize intercultural competence in a Chinese EFL (English as a Foreign Language) classroom.

Internationalization of HE institutions is now official Chinese policy applied mainly to leading universities in the better-developed regions of China. It is a major initiative to build world-class universities. The Central Government of the People's Republic of China (2010) has an educational policy for universities to engage in "broad and multiple collaborations for enhancing internationalization." It is noted that "internationalization" has now gained its first appearance in national policy. It has therefore generated serious discussion and action plans requiring provincial governments to reform HE following the successful development of the economy.

The Department of Education of Zhejiang Province (2011) located in the eastern part of the country has agreed an action plan to internationalize their HE provision. The plan reports current practice of international activities and charts the future steps of internationalization for universities. In the past five years, the HE system in this province has achieved a significant outcome, involving collaborations at all degree levels and with many joint ventures. A good example is the new campus of Nottingham University from the UK. According to the action plan, 22 thousand overseas students were accepted on campuses of universities and colleges; and approximately 2,000 students were supported to study in overseas HE institutes annually on exchange programs. The plan also provides steps for internationalization of HE over the next 10 years. The target is for the higher education of this province to attain a leading national position, by having $2 \%$ of overseas students amongst the whole student body by 2015 . This target is to be increased to $4 \%$ by 2020 , with leading universities, such as Zhejiang University, to enroll an international student body similar to developed countries.

This policy is an ambitious plan to catch up with the same level of international students enrolled in HE to that of developed countries within 10 years. This inevitably puts critical demands on teaching strategies that support intercultural learning for the increasing number of Chinese students going to study abroad and overseas students coming to study in China. The policy and action plans already acknowledge that HE in China is at the initial stage of internationalization. It needs to embrace a culture for including international students within its establishments and to develop the practice of intercultural learning within its own student body (e.g. Crabtree and Sapp 2004; Lutz 2010). This internationalization goal poses a serious challenge for HE teaching establishments to develop a new policy and practice for delivering intercultural teaching and learning. 
It is within this current context that we have developed teaching and learning strategies to generate intercultural thinking and build cross-cultural competence within the students' home country and culture at the intellectual level, in a top Chinese university, located in Zhejiang Province. In this article, we use the terms 'cross-cultural' and 'intercultural' learning interchangeably. Clearly, both terms imply the existence of ontological and epistemological differences and characteristics of teaching and learning among diverse cultures. The key difference can be explained through Vygotski's (1978) Zone of Proximal Development (ZPD) that helps us to conceptualize and identify a range of distinct learning paradigms across different languages and cultures. This learning theory approach suggests the design and integration of appropriate HE scaffolding tools and techniques to both overcome and learn about the significance of diverse cultural learning paradigms.

We illustrate this with the authors' teaching of advanced EFL writing for both academic and general purposes. Our aim was to embed critical thinking skills and predetermined patterns of thought in students that are relevant to their learning of English language and culture within the Chinese University context. The target students are either studying for a degree in English, or are involved with other subjects that involve further study in English-speaking countries. The teaching is first facilitated by the insight and experience of the instructor's intercultural learning itself between the UK and China, which is a necessary prior learning repertoire of knowledge for such learning. Then it is illuminated by the critical learning theories that have strong implications for learning across languages and cultures; for example, the notions of "cultural thought patterns" and "contrastive rhetoric" are useful tools employed to identify and visualize the ZPD (e.g. Kaplan 1966, 1987; Hofstede 1991; Bruner 1996).

\section{Contrastive Thought Patterns}

Part of the impact of globalization on HE is for the international university sector to fully understand the socio-cultural differences of languages, geography, nation-states, and races. These are not only the factors that distinguish the human race, but also the variety of cultures, which all result in our ways of knowing, thinking, viewing ourselves in the world and the shaping of our values (Kaplan1966; Bloom 1981; Hofstede 1991; Bruner 1996; Fu and Townsend 1998). Contrastive thought patterns embedded in rhetoric across diverse cultures show that thinking systems are different from person to person, with the difference being more apparent between cultural groups (e.g. Kaplan 1966; Bloom 1981; Hofstede 1991; Bruner 1996; Guan 2000). For example, Bloom's (1981) project on the linguistic shaping of thought and the impact of language on thinking in China and the West revealed that the Chinese language did not traditionally develop forms for counterfactual and entificational ways of speech; while such a communication trait is a common feature in Indo-European languages such as in English. Thus, counterfactual and entificational 
thinking is not generally developed to any significance with Chinese people located in China. In a different linguistic framework, Guan (2000, 30) compared and contrasted the various traits and idiosyncrasies of Sino-American thinking patterns, and identified that Chinese thinking tended to emphasize synthesis, while Americans engaged in analysis, which "leads to the characteristics of a Chinese priority on a holistic thinking pattern and American priority on partial." According to Guan (2000), the difference is caused by the Chinese person's brain in response to Chinese characters that define the thinking system and psychological schema required to engage with the Chinese language. In using the metaphor of a forest to stimulate individual thinking, Guan (2000) observes that Chinese people are more likely to psychologically perceive the sight of a whole forest, while Americans tend to identify individual trees. This might also explain why both cultures are conceptualized in terms of being either collectivist or individualist; and these are powerful terms that generally characterize the cultural divide between the West and East (e.g. Hofstede, 1991).

Kaplan $(1966,12 ; 1987)$ conceptualized this phenomenon in a different way, through the theory of "contrastive rhetoric" as well as through the term "cultural thought patterns" to indicate that thought patterns are influenced by cultures. Based on empirical analyses of published English written texts and compositions produced mostly by international students from different linguistic and cultural backgrounds (see also Bloom 1981; Fu and Townsend 1998), Kaplan $(1966,1987)$ then illustrated contrastive rhetoric theory. He referred to the rhetoric thought pattern derived from English language and culture, describing an English rhetoric evolved out of the Anglo-European culture, which is basically Platonic-Aristotelian. He compared this with the thought patterns reflected in English writing by those from other languages and cultures, e.g. Chinese and Arabic. According to Kaplan, the sequence of thought in an English text is depicted as linear. He traced this pattern back to philosophers of Ancient Greece, subsequently shaped by Roman, Medieval European and later Western thinkers. An English text is typified by a clear and direct statement of the author's view and argument on a topic presented in a straightforward manner. The writer then provides details or other evidence to support the logic of the original argument made. Western cultures do indeed default to the ontological assumptions of this type of individualistic logic and discourse. We would go further and link this argument to the underpinning epistemology of Western scientific thought and discovery.

Kaplan (1966) contrasted this logic and thought pattern with that of oriental students who have grown up in a non-Anglo-European cultural context. Oriental students from an educational system anchored in a Confucian heritage, such as Chinese and Korean students, do not generally use this cultural logic and type of Western 'rhetoric' when they write and express themselves. Their writing in English is described by Kaplan $(1966,18)$ as having "indirection", which often sounds "illogical" or unclear from the perspective of English readers. 
$\mathrm{Fu}$ and Townsend (1998) have also investigated the perceived writing style of international students from China studying in American universities. They found that Chinese students had been rigorously trained to strive for aesthetic forms of language in writing, aiming at applying artistic and classic literary words and phrases more than anything else. The Chinese education and training system does not prioritise the importance of developing ideas and the organizational skills required for their authoring. Consequently, there is an educational deficit for such critical thinking and written skills among many Chinese students writing in English.

Such cultural approaches to learning a foreign language and writing in the target language have further resulted in a lack of the individual writer's voice and identity, and resulted in a lack of personal ownership, whereupon the author's own ideas and view of the world are not apparent. This missing component of the individual's voice and characterization of self-identity of Chinese student EFL writing is reported as widespread and is a ubiquitous issue (e.g. Gill 2009; Gui 2009; Shen 1989). Gui (2009) has documented this issue through a longitudinal research study and she has highlighted the prevalent concern and pattern of a lack of self-identity and individual voices in Chinese students' English writing in China, where EFL is an important and therefore compulsory subject in the national curriculum from primary to university levels. She recognizes that the lack of self-identity is an outcome derived from an impersonal culture of educational provision and experience. The manifestation of this formative educational experience is seen in the EFL students' writing deficiency exhibited through two main ways that they write. The first inhibition is the reluctance to expose any personal views, and the second is the preferential and semi-unconscious use of the term "we" over "I", even when composing individual or personal views. The absence of the self and individual perspective in Chinese students' English writing has resulted, in one way, from the external imposition of English learning; and in another, from the deeply rooted tradition of a Confucian cultural notion of self, which is submerged in the collective identity, and is ultimately selfless (See also Cortazzi and Jin 1996; Hu 2002).

\section{Implications for Intercultural Teaching in both Home and International Contexts}

The contrastive rhetoric patterns gained from these applied research case studies continue to shed light on our understanding of gaps in learning outcomes originating from different cultures. This informs HE policy by articulating the variant ZPD, giving us an insight of what to do about solving the challenges in actual international teaching and learning situations that operate at the interfaces of divergent cultures. Our research has informed the following postulate: that international teaching strategies need to focus on enabling learners to critically engage in identifying and dealing with any personal prior cultural constraints and acquire different thinking devices (or schemas) to function in the target language and culture competently. It could lead to a potential positive educational outcome for both society and the 
learners who will become tomorrow's global citizens.

Contemporary HE in both international and home (Chinese) contexts now comes with the expectation that learning a foreign language is something integrated into all the various subject areas. International students are supposed to have minimum language proficiency for studying a degree in an overseas university, i.e. typically in English-speaking settings. In addition, assessment of courses, degrees and communication between teachers and students is usually based on written evidence, in the form of course papers, dissertations and emails (e.g. Andrews 2003; Fersten and Reda 2011). It is a misleading notion to assume that an international student is able to write their course papers and dissertations fluently in English just because they have learned to control the phonology and the syntax of English language through passing a standard EFL English testing exam. Such standard English preparation courses come without any explicit training for acquiring the necessary thinking skills, or being informed of the culturally-assumed thought and reasoning patterns, and logics required for the academic written assessment evidence to be accepted by their English supervisors and universities. This is also the case with native English speaking students in HE (e.g. Leedham 2009; Fersten and Reda 2011). Fersten and Reda (2011 ,172; 173) have pointed out "writing issues persist well beyond the composition classroom and are perhaps even more problematic in content-area classes." We are drawn to the fact that writing remains a powerful gatekeeper in schools and a general educational goal for "the educated student and citizen". They continue to call for "various approaches to the teaching of writing in order to decrease the significant gaps that exist between the advantaged and the disadvantaged."

This cultural deficit is also the case for students studying a foreign language and culture; or when university staff members are teaching a student cohort for a degree in their home country in the face of internationalization in HE (e.g. Lutz 2010). EFL and its culture has become a degree widely studied at both undergraduate and postgraduate levels in many non-English-speaking countries. Sadly, many of these programmes have seldom moved their students beyond the mere manipulation of vocabulary or the syntax of technical English. This technical approach avoids the difficulties international students' face regarding problems associated with understanding cultural differences and developing new ways of communication suitable for a native English audience. Leading universities in China have many students that possess a large English vocabulary, but in practice are not familiar with the correct social context for expression in a fluent style, i.e. they lack personal knowledge and experience of the thought patterns required for fluency.

We maintain that in order for students to master fluency in any modern language they need to engage in a synthesis of both the language and its related living culture from which the language embeds its hidden meanings and value systems. In order to write authentically in the English language, it therefore requires a personal paradigm shift 
with the learner engaged in a radical change of thinking and adopting a new cultural perspective. The English cultural context places the concept of 'the individual' at the heart of its ontological, cultural, social, educational and political assumptions. In Western contexts, such assumptions of individuality imply that the student ought to come more to the fore; whereupon there is an expectation that personal opinions are valued and therefore expressed frankly and without embarrassment (Kaplan 1966; Huang and Brown 2009). Within this cultural context the Chinese learners' social identity needs to migrate from being expressed collectively to one of individual expression. This means that Chinese students wishing to engage and empathize within an English (and generally Western) cultural context need to think and learn in a different way. This requires both an individual and cultural paradigm shift to achieve intercultural competence in the cross-cultural learning context, a move away from thinking of themselves as part of a collective identity and 'voice', and transformation towards uniquely thinking of themselves dissimilarly as individual persons in their new found writing 'voice' (Shen 1989; Gale 1994; He 2002; Wu 2006; Zhao 2009). Developing and authoring in a unique personal voice enables the Chinese EFL student to cross cultural boundaries and produce a more authentic piece of written work in English. Teaching EFL writing skills should, therefore, include such transformative thinking and writing devices in students and be placed at the centre of re-thinking the entire curriculum design and delivery of EFL, if not all other subject fields. This profound idea and the resultant pedagogical conceptual framework have been not only articulated, but also acted upon for important experimental changes in the design and delivery of the EFL curriculum in the author's university classroom.

\section{Teaching to Cross the Border of Cultures}

The first author, as a Chinese academic, obtained her MA and $\mathrm{PhD}$ qualifications from a British university and resumed working in a university in China. Because of this profound educational and intercultural learning experience, the author found that she was no longer able to teach English at degree levels in the previous way; treating it as a mere linguistic phenomenon and technical exercise of instruction. The teaching of English writing has therefore being reorganized in an attempt to reach students by embedding critical thinking skills and capacitating the cultivation of an original learner voice, self identity and an individualised pedagogy. A holistic set of personal attributes and dispositions that are now deemed as necessary curriculum elements in developing EFL thinking and writing skills. In short, we recommend replacing the teacher at the centre of instruction to facilitating a more student-centred learning paradigm, much akin with Boud's (1985) theory of reflective learning environments and Kolb's (1984) philosophy of experiential learning.

However, these radical learning objectives are not realized without resistance from and anxieties exhibited in students drawn from the home Chinese culture. While these pedagogical strategies have become familiar in most universities in the English-speaking world, this is not the case in China, and understandably creates 
potential social and cultural tension in learning and teaching situations. This cultural problem requires pre-emptive teaching with a prior learning strategy to help Chinese students to safely cross the border of cultures and languages intellectually and cognitively, without physically leaving their home country. They need to be carefully introduced to a new social and cultural learning paradigm and provided with the personal 'tools' to survive and prosper within this new territory. The potential cultural benefits are enormous. New dispositions and abilities towards critical and creative thinking are not only higher or deeper orders of learning, but something many Asian countries have been striving for over several decades, e.g. Singapore's national strategy for embedding critical and creative thinking into the national curriculum under its policy of 'Thinking Schools Learning Nation' (Saravanan 2005). Howard Gardner's (1983) model of Multiple Intelligences was used for enabling the thinking school model used in Singapore, in order to develop critical and creative thinking capacities in students. It has significant implications for other Asian countries, including China, to transform educational systems that rely too heavily upon 'collectivist' pedagogies such as rote learning.

\section{Developing Original Ideas}

From an intercultural perspective, the authors' teaching aim is to help students master the deep cultural mechanisms required for producing English fluency. These cultural mechanisms include developing various ideas linked to eliciting a point of view that is organized by an English rhetoric thought pattern, starting first with paragraphs and later building up to essays. These embedded patterns of thought clearly reflect the author's voice and view, which forms the basis of developing original student-derived written work. The main difficulty experienced throughout the course was to get students to elicit their original thoughts and ideas directly and clearly in their opening paragraph or introduction of their essays, and to then identify the relevant supporting details. Instead, they felt more comfortable to slowly introduce and reveal it at the end of their papers. Some form of critical thinking scaffold (Coombs 2002) to accelerate this kind of thinking pattern and disposition towards learning is used.

In the 'writing' course curriculum, three sessions were deliberately arranged to re-establish the student's understanding of writing in English through topics such as:

- Learning to write and writing to learn

- Thinking represented in languages

- Writing to cross cultures

The purpose was to integrate critical thinking and develop student ideas within the language and writing tasks; and a contrastive cultural perspective is supplied for students to reflect on why they have approached English writing the way they did with rote learning techniques and the resultant absence of ideas. We addressed this by engaging students in some cultural exercises to examine how they had previously 
been taught English writing. This prior learning and awareness raising exercise was introduced to students' as a form of induction during their first writing assignments. Students were inducted to become self-aware of such prior cultural learning consequences and the effect that this had upon their current approaches to English writing. In one classroom session we explored the students' experiences for meeting the requirements of their prior English writing tasks across all stages of school. Students' recalled that previous requirements overwhelmingly addressed the numbers of words produced for their EFL writing tasks. For instance, when they transited from junior to senior secondary school, the English writing required for the examination was 120 words, with 150 words for the university entrance examination. The word length increased to about 200 words for College English Test Band 4, a requirement for their university degrees (Gui 2009). Students recalled that it was common practice in Chinese examinations to be given a topic and the main idea for them to write in English, thereby depriving them of developing their own ideas and voices.

The epistemological assumption explored was that if they, as Chinese students, accumulate more words and read "good" English texts written by English writers and scholars; then, by mimicking this process, they too would be able to write good English. Students gradually recognized, however, that this in fact did not take place and that something (self-identity linked to personal expression) was crucially missing. They initially felt at a loss when first asked to write about their own ideas. With these prior cultural exercises and self-examination of the educational provision and learning environment experienced, the students' gradually realised that their former system of education could not nurture original thinking. The alternative 'person' centred approach to education therefore became the developmental zone for learning and eventually generated a motivational "hunger" for the creation of ideas. The students' gradually engaged in the learning conversations and activities where they were obliged to search their own experiences in order to generate and acquire original ideas and produce authentic English texts.

\section{Cultivating Self-identity with a Biographical Method}

The missing nature of self-identity in Chinese students' writing in English (Gui 2009) is often exposed when they are expected to write within a different cultural paradigm. When learning engages students in the growth of their identity and raises such self-awareness, it is understood to represent meaningful learning (Bruner, 1996). Coming from a Chinese background, Shen (1989), He (2002) and Zhao (2009) have reported on their own experiences of transformation as they engaged in the rules and cultural assumptions of English composition. They documented their intercultural learning resulted in reconciling their collectivized Chinese identity characterised as "we" with an individualized English identity characterized with "I". They noted that their cross-cultural backgrounds shaped their approaches to writing in English, and how learning of and writing in English redefined their self-identities, with, no doubt, profound consequences and intellectual benefits. 
A key accompaniment to any original idea being developed was the cultivation of self-identity, which guided the whole process of teaching and writing of the course. The biographical method was a key technique that was adopted and adapted to cultivate author identity within written expression. Most of the teaching exercises are centred on creating and discovering the self. This was achieved through three projects with key student-centred assignment tasks that included: a one-paragraph essay of self-introduction; preparing a job application package of a cover letter, CV and personal statement; and, a lengthy description of a Chinese cultural viewpoint for a five-paragraph essay, later, a research idea for an academic paper.

Steps toward participatory and meaningful learning are made in the process of placing the student's lived life and home culture at the centre and as the focus for self-observation. This student exercise aims to elicit and identify significant life learning points and critical incidents that derive from their individual experiences and hence uniquely differentiate one person from another. The social dynamics created by the differences identified between individuals in the classroom inspired them to increase their distinctiveness as well as self-esteem, and overall confidence to engage in this type of learning and writing environment. For example, after weeks spent on self-introduction with a free writing exercise, then practised writing one-paragraph with the same topic for a topic sentence and supporting details within one paragraph. The students struggled to develop their own 'voice' as a writing space. Most of them found it very difficult to viewpoint aspects of their lives and articulate the sense of being a person. The "indirect" (Kaplan 1966) approach to writing in English is still obvious in their first attempts. About $10 \%$ of students used the third person pronoun when introducing themselves, and about $20 \%$ started with playing or explaining meanings of their names, and $20 \%$ were writing about their hometowns. In feedback, the teacher commented that most of the self-introduction writing assignments had not come to the point of the "self" at all. Students were advised that the effect of their writing of self-introduction sounded like "I am them" or "They are me".

Despite these understandably difficult learning journeys, a few students produced some excellent one-paragraph and five-paragraph essays. As one student wrote in his one-paragraph assignment on self-introduction: "The greatest joy of my life derives from reading. ...I love to read with peace of mind in a fine afternoon. ... Sitting beside piles of books gives me a sense of security and satisfaction. ... My dad and I always talked about the book I'd just read when we were taking a walk...(Du 2010). As a result, genuine student individuality and engagement emerged in the classroom, and rote learning and imitation were discarded.

\section{Conclusion}

Learning a subject in a different culture and teaching a foreign language at an advanced level in the student's home culture provides learners' with the opportunity to 
be exposed to a new and possibly different thinking system. This new conceptual framework moves away from the normal mode of thinking derived from a student's first language and native culture. We postulate that this personal and cultural paradigm shift is essential in order that the individual student in China and from elsewhere can actualize intercultural learning and achieve the capabilities argued by other critical theorists (Kaplan, 1966; Atkinson, 2003; Lutz, 2010).

We strongly recommend that these ideas form the basis of radical curriculum reform with new pedagogical strategies. This can be addressed through reconceptualising curriculum and classroom practices so as to transform rote learning and engage students in a new teaching and learning space. With such curriculum strategies, learning becomes quality assured and the student's wellbeing is enhanced; whereupon the learner is placed at the centre and learning becomes much more "enjoyable" and relevant.

The policy of HE internationalization in China seeks to emulate the well-established practice found in "Western" settings (e.g. Stephens, 2007; Gu, 2009). There is no doubt that internationalization of HE can create new opportunities for advancing learning across the interfaces of different cultures and languages. We argue that HE pedagogy can now recognize that cultural differences are no longer the problem, but instead offer potentially valuable resources and developmental zones for learning that will enrich and deepen the role and purpose of international higher education. The outcomes from levering such a curricular and pedagogical approach towards developing cultural literacy is not only to embed the higher learning benefits of original, critical and creative thinking, but also to equip the student as a future global citizen.

\section{References:}

Andrews, R. 2003. The end of the essay? Teaching in Higher Education 8:1, 117-28.

Atkinson, D. 2003. Writing and culture in the post-process era. Journal of Second Language Writing 12, 49-63.

Bloom, A. H. 1981. The linguistic shaping of thought: A study in the impact of language on thinking in China and the West. Hillsdale, NJ: Lawrence Erlbaum.

Bodycott, P. and Walker, A. 2000. Teaching abroad: Lessons learned about inter-cultural understanding for teachers in Higher education. Teaching in Higher Education 5: 1, 79-94.

Boud, D., Keogh, R. and Walker, D. 1985. Reflection: turning experience into learning. London: Routledge Falmer. 
Bruner, J. 1996. The culture of education. CM: Harvard University Press.

The Central Government of the People's Republic of China, 2010, The National Plan for Mid-long Term Education Reforms and Development (2010-2020), last retrieved May 2011 from http://www.gov.cn/jrzg/2010-07/29/content_1667143.htm.

Crabtree, R. D. and Sapp, D. A. 2004. Your culture, my classroom, whose Pedagogy? Negotiating effective teaching and learning in Brazil. Journal of Studies in International Education 8:1,105-132.

Coombs, S. 2002. Using critical thinking scaffolds to support curriculum project work. In A. Chang \& C. Goh (Eds.), Teachers' handbook on teaching generic thinking skills. Singapore: Prentice Hall.

Cortazzi, M. and Jin, L. X. 1996. Cultures of learning: Language classrooms in China. In H. Coleman (ed.) Society and the language classroom (pp. 169-206). Cambridge: Cambridge University Press.

Dolby, N. 2010. Internationalizing higher education: The development of practice and policy in South Africa. 112:7,1759-1791.

Du, Z. Y. 2010. Self-introduction (Student Writing for Course Assignment).

Fersten, L. and Reda, M. 2011. Helping students meet the challenges of academic writing, Teaching in Higher Education 16:2, 171-182.

Fu, D. \& Townsend, J. 1998. Cross-cultural dilemmas in writing: Need for transformations in teaching and learning. College Teaching 46:4,128-132.

Gale, X. L. 1994. Conversing across cultural boundaries: Rewriting "self". Journal of Advanced Composition 14, 455-462.

Gardner, H. 1983. Frames of mind: The theory of multiple intelligences. New York: Basic Books.

Gibson, R. 2010. The 'art' of creative teaching: Implications for higher education. Teaching in Higher Education 15: 5, 607- 613

Gill, S. 2009. ed. Exploring selfhood, finding ourselves, finding our stories in life narratives. Sussex: Guerrand-Hermes Foundation.

Gu, Q. 2009. Maturity and interculturality: Chinese students' experiences in UK higher education, European Journal of Education 44:1, 38-52. 
Guan, S. 2000. A comparison of Sino-American thinking patterns and the function of Chinese characters in the difference. in R. Heisey, Chinese perspectives in rhetoric and communication (pp. 25-45). Connecticut: Ablex Publishing Cooperation.

Gui, L. 2009. Critical pedagogy in EFL college writing instruction in China: an untested feasibility. Hangzhou: Zhejiang University Press.

He, M. F. 2002. A Narrative inquiry of Cross-cultural lives: Lives in Canada. Journal of Curriculum Studies 34:3, 323-342.

Hofstede, G. 1991. Cultures and organizations: software of the mind. New York: McGraw-Hill.

Hu, G. W. 2002. Potential cultural resistance to pedagogical imports: The case of communicative language teaching in China. Language, Culture and Curriculum 15:2, 95-105.

Huang, J. and Brown, K. 2009. Cultural factors affecting Chinese ESL students' academic learning. Education129:4, 643-650.

Ippolito, K. 2007. Promoting intercultural learning in a multicultural university: ideals and realities. Teaching in Higher Education 12: 5, 749 -763

Kaplan, R. B.1966. Cultural thought patterns in inter-cultural education. Language Learning $16: 11,1-20$.

Kaplan, R. B. 1987. Cultural thought patterns revisited. In U. Connor \& R. R. Kaplan (eds). Writing across languages: Analysis of L2 Texts (PP.9-21). MA:

Addison-Wesley.

Kolb, D. 1984. Experiential learning: Experience as the source of learning and development. Englewood Cliffs, N.J., Prentice-Hall.

Leedham, M. 2009. From traditional essay to "Ready Steady Cook" presentation: Reasons for innovative changes in assignments, Active Learning in Higher Education 10, 191-206.

Lutz, J. 2010. Becoming global citizens without leaving home. Teaching in Higher Education 15:6, 715-720.

Saravanan, V. 2005. 'Thinking Schools, Learning Nations': Implementation of curriculum review in Singapore. Educational Research for Policy and Practice 4:2-3, 97-113.

Stephens, D. ed. 2009. Higher education and international capacity building: 
Twenty-five years of higher education links. Oxford: Symposium Books.

The Department of Education of Zhejiang Province, 2011, Action plan for internationalization of HE (2010-2020), last retrieved May 2011 from http://www.zjedu.gov.cn/gb/articles/2011-01-17/news20110117163513.html

Tani, M. 2008. Raising the in-class participation of Asian students through a writing tool. Higher Education Research \& Development 27: 4, 345-356.

Vygotsky, L.S. 1978. Mind in society. Cambridge, MA: Harvard University Press.

Wu, Z. J. 2006. Understanding practitioner research as a form of life: An Eastern Interpretation of exploratory practice. Language Teaching Research 10:3, 331-350.

Zhao, H. Q. 2009. Realization of the self, a process of discovery and creation through cross-cultural learning." In S. Gill: Exploring selfhood: Finding ourselves, finding our stories in life narratives (pp.241-259). Sussex: Guerrand-Hermes Foundation for Peace. 